\title{
O PAPEL DOS ARQUIVOS PESSOAIS E INSTITUCIONAIS PARA O ESTUDO DE GESTÃO ADMINISTRATIVA: UM ESTUDO SOBRE OS DIRETORES DA FCM/UNICAMP
}

http://dx.doi.org/10.5902/2318133834219

\author{
Ivan Luiz Martins Franco do Amaral ${ }^{1}$ \\ Everardo Duarte Nunes ${ }^{2}$
}

\begin{abstract}
Resumo
Neste artigo tem-se como principal objetivo discutir a questão dos arquivos pessoais e institucionais para os estudos de gestões administrativas, tomando como estudo de caso a Faculdade de Ciências Médicas da Universidade Estadual de Campinas - FCM/Unicamp -, no período de 1963-2014. A proposta geral da pesquisa foi a de realizar um estudo histórico-social da trajetória das gestões dos diretores durante cinquenta anos, tendo como principal referência os conceitos de gestão e gestão institucional, abrangendo o estudo de quatorze gestões. Além de destacar a conceituação sobre arquivos institucionais e pessoais, apresenta-se uma breve história dos arquivos e da arquivística brasileira e de como está organizado o Setor de Arquivos da Unicamp e do Centro de Memória e Arquivo da FCM/Unicamp. Também são apresentadas as fontes e os tipos de documentos utilizados na pesquisa sobre as gestões dos diretores.

Palavras chave: arquivos; arquivos pessoais; arquivos institucionais; gestão administrativa; gestão documental.
\end{abstract}

\section{THE ROLE OF PERSONAL AND INSTITUTIONAL ARCHIVES FOR THE STUDY OF ADMINISTRATIVE MANAGEMENT: A STUDY ABOUT FCM / UNICAMP DIRECTORS}

\begin{abstract}
The main objective of this article is discussing the role of personal and institutional archives for administrative management studies, taking the Faculty of Medical Sciences, University of Campinas - FCM/Unicamp - as a case study, period 1963-2014. The general proposal of the research is executing a historical-social study of the management directors' trajectory during fifty years, having as main reference the concepts of management and institutional management, covering the period of 14 administrations. In this article, in addition to highlighting the concept of institutional and personal archives, a brief history of archives and the Brazilian Archives' history is presented, as well as how Unicamp's Archives sector and Memory and Archive of FCM/Unicamp are organized. It is also presented the sources and types of documents used in the survey about directors' management.
\end{abstract}

Key-words: archives; personal archives; institutional archives; administrative management; document management.

\footnotetext{
${ }^{1}$ Universidade Estadual de Campinas, Brasil. E-mail: ivanfa@fcm.unicamp.br.

2 Universidade Estadual de Campinas, Brasil. E-mail: evernunes@uol.com.br.

\begin{tabular}{l|l|l|l|l|l|} 
Regae: Rev. Gest. Aval. Educ. & Santa Maria & v. 8 & n. 17 & Pub. contínua 2019 & p. 1-15
\end{tabular}
} 


\section{Introdução}

A este artigo tem-se como centralidade discutir a questão dos arquivos $\checkmark$ pessoais e institucionais para os estudos de gestões administrativas, tomando como estudo de caso uma instituição de ensino superior: a Faculdade de Ciências Médicas da Universidade Estadual de Campinas - FCM/Unicamp no período de 1963-2014.

A proposta geral da pesquisa foi a de realizar um estudo histórico-social da trajetória das gestões dos diretores durante cinquenta anos, tendo como principal referência os conceitos de gestão e gestão institucional, abarcando o estudo de 14 gestões (Amaral e Nunes, 2017).

Além dos aspectos específicos dessas gestões, buscou-se cotejá-las com as questões referentes ao ensino superior das ciências da saúde e das principais questões sociais, políticas, econômicas e sanitárias no período em que desenvolveram suas atividades.

A metodologia geral do trabalho assenta-se na pesquisa social de Bruyne et al (1977) conhecida como metodologia quadripolar. Nela os autores procuram trabalhar de forma interdependente quatro polos: epistemológico, teórico, morfológico e técnico. Assim, além de destacar a conceituação sobre arquivos institucionais e pessoais é apresentada uma breve história dos arquivos e da arquivística brasileira e de como está organizado o Setor de Arquivos da Unicamp e do Centro de Memória e Arquivo da FCM/Unicamp. Também são apresentadas as fontes e os tipos de documentos utilizados na pesquisa sobre as gestões dos diretores.

\section{Arquivo: conceito e história}

Compreendemos como arquivo a "acumulação ordenada dos documentos, em sua maioria textuais, criados por uma instituição ou pessoa, no curso de sua atividade, e preservados para consecução de seus objetivos, visando a utilidade que poderão oferecer ao futuro" (Paes, 2004, p.16). Este conceito traduz o que o Dicionário Brasileiro de Terminologia Arquivística propõe: "Arquivo é o conjunto de documentos produzidos e acumulados por uma entidade coletiva, pública ou privada, pessoa ou família, independente da natureza do suporte" (Arquivo Nacional, 2004, p. 27).

Se voltarmos a atenção para as origens da palavra verificamos que arquivo "provém do grego archeion que seria composto de dois elementos: arkhaios, antigo e epo, dispor, ter cuidado, e deu origem em latim archivum. Arquivo significaria, portanto, a arrumação de coisas antigas" (Hora; Saturnino; Santos, 2010, s.p). Seguiremos os passos deste trabalho que oferece detalhada descrição sobre a história dos arquivos, situando suas origens na pré-história.

Segundo Hora; Saturnino; Santos (2010), "em Roma, a administração do Império levou a grandes progressos no domínio dos arquivos". Lembram que "Certos critérios usados na organização de Arquivos pelos Romanos continuam ainda hoje válidos. Criaram uma rede de serviços e um corpo profissional especializado" (s.p). 
Os autores seguem pela Idade Média quando apontam que houve declínio na Arquivologia, centralizada pela igreja "que detinha os saberes e monopolizava todo o conhecimento da época", e criaram os denominados "arquivos eclesiásticos, onde as informações contidas ficavam à mercê de religiosos (abades, frades, padres, monges e principalmente o papa)" (Hora; Saturnino; Santos, 2010, s.p).

Passando pela idade moderna citam que foi importante o papel do renascimento e da reforma protestante na arquivologia, mas "com o advento do lluminismo, os arquivos passaram a ser fontes de pesquisa relacionadas com a história, onde os documentos guardados serviam como instrumentos de pesquisa, para tentar explicar fatos decorrentes da época, dando origem aos documentos de cunho acadêmico" (Hora; Saturnino; Santos, 2010, s.p).

Com a idade contemporânea ocorreu uma grande explosão documental e informacional com o advento de novas tecnologias (computador, redes de TV, etc.). E na arquivística, o que acontece? "Surgem novos princípios e a população começa a ver a ciência de uma maneira que poderia resolver os problemas informacionais, organizandoos e conservando-os, objetivando sua difusão de forma clara e eficaz para toda a população" (Hora; Saturnino; Santos, 2010, s.p).

\title{
O universo dos arquivos pessoais e institucionais
}

Além da questão conceitual, outro ponto a ser destacado refere-se à classificação dos arquivos, ou seja, a distinção entre arquivos públicos e privados, pessoais e institucionais. Esse tema tem sido abordado por diversos estudiosos como Rios e Cordeiro (2010); Sousa (2003); Sousa (2006), dentre outros. Sousa (2003) aponta que a

\begin{abstract}
A classificação, até as primeiras décadas do século XIX, era elaborada sem levar em conta a origem administrativa dos documentos. Destaca, ainda, como importante, que foi somente em 1841, por meio de uma circular, que se registrou a noção de "fundos de arquivos", [objetivando] agregar os documentos por fundos, isto é, reunir todos os títulos (documentos) provenientes de um corpo, de um estabelecimento, de uma família ou de um indivíduo, e dispor segundo uma determinada ordem os diferentes fundos [...]. E para evitar qualquer tentativa de constituição de coleções, a circular acrescentava: (...) os documentos que apenas têm relação com o estabelecimento, um corpo ou uma família não devem ser confundidos com fundo desse estabelecimento, desse corpo ou dessa família. (p. 248)
\end{abstract}

Para Souza (2003), "os princípios de respeito aos fundos e o da ordem original são as bases que fundamentam toda a atividade de classificação, da mesma forma [...] a Teoria das Três Idades estabelece as estratégias de avaliação" (p. 250). As extensas e detalhadas e importantes reflexões realizadas por Sousa (2006) não são aqui retomadas, mas conservamos uma passagem que nos parece fundamental para os nossos propósitos:

A elaboração desses dois princípios [origem e ordem interna] marca, sem dúvida nenhuma, uma mudança significativa nos fundamentos e nas práticas de classificação de documentos arquivísticos. Podemos dizer que tem início a passagem da classificação com bases intuitivas para uma outra sedimentada no caráter e nas especificidades do objeto. Em 
comparação com as práticas anteriores, que se ancoravam em aspectos não representativos dos documentos arquivísticos, percebemos um grande avanço. O caminho, entretanto, é um pouco mais longo. As lacunas ainda existem. (Sousa, 2006, p.138)

Segundo a legislação brasileira, lei n. 8.159, de 8 de janeiro de 1991, os arquivos privados são "os conjuntos de documentos produzidos ou recebidos por pessoas físicas ou jurídicas, em decorrência de suas atividades" (capítulo III, art. 11), e os arquivos públicos "são os conjuntos de documentos produzidos e recebidos, no exercício de suas atividades, por órgãos públicos de âmbito federal, estadual, do Distrito Federal e municipal em decorrência de suas funções administrativas, legislativas e judiciárias" (capítulo II, art. 7).

A constituição prevê, ainda, a viabilidade de arquivos privados pertencerem aos órgãos públicos, em caso de avaliação de interesse, com a ressalva da necessidade de autorização do proprietário do acervo (Presidência da República, 1991).

As descrições apresentadas esclarecem apenas a distinção entre os dois arquivos, sem informações sobre as semelhanças e mesmo sobre o caráter híbrido de conjuntos documentais, ou seja, contendo fundos pessoais e institucionais fisicamente no mesmo local. Sobre esta questão é interessante acompanhar como foi analisada pelo arquivista Terry Cook no Seminário Internacional de Arquivos Pessoais, realizado na década de 1990. Segundo Cook (1998) as semelhanças dos arquivos são as seguintes:

Primeiro, ambos são artefatos de registro derivados de uma atividade; os arquivos são evidências das transações da vida humana, seja ela organizacional, e, por conseguinte oficial, seja individual, e, portanto pessoal. Diversamente de livros, programas de televisão ou obras de arte, eles não são intencionalmente criados por motivos próprios, com a possível exceção dos textos autobiográficos, mas surgem, antes, dentro de um contexto, como parte de alguma outra atividade ou necessidade, seja pessoal, seja institucional. Em segundo lugar, os arquivistas, tanto nos arquivos públicos quanto nos pessoais, frequentemente usam procedimentos técnicos e métodos práticos semelhantes, em termos de como acessam, descrevem, armazenam fisicamente e conservam os arquivos e os colocam à disposição para fins de pesquisa. (p. 131)

Os fundos privados e institucionais apresentam características que os aproximam e distanciam. Os cinco princípios da arquivística nos auxiliam a diferenciar os documentos de arquivos aos de outra natureza, como o museológico e de biblioteca. Nesse sentido, Ducrot, (1998) lembra que "os documentos não devem ser tratados isoladamente segundo um quadro metódico, e sim ficar agrupados em seus fundos de origem, sendo o fundo o conjunto de arquivos que provêm de uma mesma entidade - repartição, órgão público, pessoa, família, empresa etc." (p. 154).

Exemplo de estudo que marca a diferença dos arquivos pessoais e institucionais é trazido por Santos (2012) em sua pesquisa sobre Uma abordagem arquivística: os documentos de um laboratório das ciências biomédicas. Nesse estudo situa a existência de arquivos pessoais nos laboratórios institucionais ordenados com documentos da instituição, quando conservados no mesmo espaço. 
Analisando, ainda, a pesquisa de Santos (2003), observa-se a existência de documentos que mesmo apresentando grande pessoalidade podem ser considerados como institucionais, em decorrência de sua origem. Como exemplo podem ser citados os cadernos de laboratório dos pesquisadores, estes são utilizados na instituição para realização de uma atividade pessoal, mas que são organizados como pertencentes ao laboratório de pesquisa, portanto, institucionais.

\section{Breve história da formação dos arquivos brasileiros}

A arquivologia no Brasil se iniciou na década de 1960. Antes "os arquivos funcionavam como simples depósitos, sem nenhum controle, sem nenhuma metodologia, ou seja, o tratamento aos arquivos era totalmente empírico" (Silva, 2002, p. 14). Segundo Silva (2002), José Honório Rodrigues, diretor do Arquivo Nacional, em 1958, constatou a desordem dos arquivos por "falta de uma política orientada de recolhimento e de seleção e eliminação dos documentos" (p. 16), tendo listado uma série de medidas para melhorias no Arquivo Nacional; investimento em recursos humanos com maior capacitação, melhorias na infraestrutura dos prédios para combate a fogo, umidade, altas temperaturas e catástrofes naturais. Lopes, (apud Silva, 2002), anota que, "inauguram, com José Honório, na década de 1960, o costume de pensar e produzir conhecimentos sobre o assunto".

Os estudiosos estabelecem que a mudança na política arquivística no Brasil iniciouse após o relatório do diretor do Arquivo Nacional, no final da década de 1950 e chega ao seu ponto mais alto no início da década de 1960. Neste período o país recebeu a visita de dois ilustres arquivistas: Schellenberg e Boullier. Segundo eles, a situação arquivística brasileira era bastante precária e empiricista, necessitando de transformações praticamente em todos os pontos colocados em pauta. Para Silva (2002), esses arquivistas deixaram "lições importantíssimas sobre a classificação moderna e o arranjo dos documentos, sobre as concepções de fundo adotadas internacionalmente e sobre a aplicação do Princípio da Proveniência" (p. 28). Das lições deixadas ressalta-se "a ideia de que os arquivos constituiriam uma unidade indivisível do patrimônio documental nacional, a qual acarretaria numa unidade e indivisibilidade da administração do Estado" (Silva, 2002, p. 29) e a formação, em 1961, pelo Ministério da Justiça e Negócios Interiores, de uma Comissão responsável pelo projeto e constituição do Sistema Nacional de Arquivos no Brasil.

A análise da indivisibilidade e a constituição de um sistema arquivístico colocaram o Arquivo Nacional como responsável por todos os arquivos da União pela política de organização, transferência, seleção e guarda dos mesmos, favorecendo a conservação do patrimônio documental do país.

O fortalecimento da arquivologia brasileira apareceu na década de 1970 com a criação da Associação dos Arquivistas Brasileiros, a realização do $1^{\circ}$ Congresso Brasileiro de Arquivologia, a publicação da revista Arquivo \& Administração, publicação oficial da Associação dos Arquivistas Brasileiros, a criação dos cursos universitários de Arquivologia e a regulamentação da profissão de arquivista e técnico de arquivos no país; porém melhorias ainda eram necessárias. Silva (2002) relata que, em 1978, Durchein, consultor francês em arquivologia, avaliou a estrutura e política arquivística do Brasil e constatou a necessidade de melhorias na estrutura arquitetônica dos arquivos, realização 
de uma reforma na grade do curso superior em arquivística, e a criação de um Sistema Nacional de Arquivos. Este sistema, denominado Sinar, foi criado somente em 1991, pela lei n. 8.159, com objetivo de programar a política nacional de arquivos públicos e privados, visando à gestão, à preservação, e ao acesso aos documentos de arquivo.

\section{As universidades e os arquivos}

Conjuntamente ao processo de identificação arquivística no Brasil, pelo Arquivo Nacional, na década de 1980 "as universidades se movimentavam para a organização de seus próprios arquivos a reboque das instituições públicas de uma forma geral, que vinham definindo políticas de gestão de documentos" (Martins, 2012, p. 47). Anterior a esse momento constata-se uma incipiente organização tentando resgatar documentos administrativos e arquivos pessoais.

Na década de 1990 houve impulso à Arquivística, pois, além da criação do Sistema Nacional de Arquivos, também foi constituído o Conselho Nacional de Arquivos - Conarq , que tem por finalidade definir a política nacional de arquivos públicos e privados. $\mathrm{O}$ art. 26 da lei n. 8.159/91 foi regulamentado pelo decreto n. 4.073, de 3 de janeiro de 2002. De acordo com esse dispositivo legal, o Sinar tem por finalidade implementar a política nacional de arquivos públicos e privados, visando à gestão, à preservação e o acesso aos documentos de arquivos.

Integram o Sinar, que tem como órgão central o Conarq, o Arquivo Nacional; os arquivos do Poder Executivo Federal; os arquivos do Poder Legislativo Federal; os arquivos do Poder Judiciário Federal; os arquivos estaduais dos poderes Executivo, Legislativo e Judiciário; os arquivos do Distrito Federal dos Poderes Executivo, Legislativo e Judiciário; os arquivos municipais dos poderes Executivo e Legislativo.

Destaque-se como evento importante no início da década de 1990 a realização em novembro de 1991, na Unicamp, em Campinas, São Paulo, do 1ํ Seminário Nacional de Arquivos Universitários, considerado um marco na história dos arquivos universitários no Brasil. O evento fez parte das atividades realizadas na universidade em comemoração aos seus vinte e cinco anos de fundação, sob patrocínio financeiro da Fundação de Amparo à Pesquisa do Estado de São Paulo e do Banco do Brasil. Durante a realização do seminário foi inaugurado o novo edifício do Arquivo Central da Unicamp, com objetivo de preservação, difusão e normatização arquivística na Universidade.

No discurso de abertura do seminário, o reitor da Unicamp salientou a importância do evento para todas as universidades do país, para conscientização e preservação correta de seus acervos documentais, bem como

não tinha em mente beneficiar apenas a comunidade interna, matéria que representa por si só um objetivo nobre e ambicioso, tratando-se de um assunto sensível como é aquele de prover nossos pesquisadores e estudantes dos documentos necessários à sua atividade. [...] $\mathrm{O}$ objetivo maior é o de implantar uma mentalidade arquivológica em nossas universidades, como forma de preservar suas descobertas administrativas, pondo ao alcance da comunidade nacional e do administrativo público as propostas de solução engendradas por nossos pesquisadores. (Vogt, 1991, p. 9) 
De forma detalhada, Jilek (s/d) citado por Belloto (1989) assim se expressa sobre as funções fundamentais dos arquivos universitários:

1- reunir, processar, divulgar e conservar todos os documentos relativos à administração, histórica e ao funcionamento/desenvolvimento da universidade; 2- avaliar e descrever estes documentos tornando possível seu acesso, segundo as políticas e procedimentos elaborados especificamente para estes fins; 3- supervisionar eliminação, ter o controle da aplicação das tabelas de temporalidade, a fim de que nenhum documento de valor permanente seja destruído. Disto tudo depreende-se seu segundo grande papel que é o de: 1 - fornecer aos administradores as informações requeridas ao menor prazo possível; 2- fazer as demandas de informação e de pesquisa requer-se do serviço de arquivos universitários que proponha e coordene a uniformização de métodos de classificação de documentos dentro das unidades universitárias com afinidade de recuperação acelerada dos documentos necessários aos administradores. (p. 23)

\section{A história dos arquivos da Unicamp e da Faculdade de Ciências Médicas}

O espaço responsável pela normatização dos documentos institucionais recebidos e expedidos pela Universidade Estadual de Campinas e que busca coordenar a política e a gestão arquivística na universidade, visando agilização da informação, eficiência administrativa e a preservação da memória institucional é o Sistema de Arquivos da Unicamp - Siarq -, coordenado pelo Arquivo Central.

Contar a história da criação do Arquivo Central da Universidade é importante, pois os arquivos que estão sendo analisados na pesquisa das administrações da Faculdade, além dos demais acervos localizados no Centro de Memória e Arquivo da FCM/Unicamp, contemplados neste trabalho, recebem desde a sua criação orientações normativas do Sistema de Arquivos da Unicamp.

Lembramos que os arquivos dos fatos antecedentes à criação da Universidade, compostos pela comissão organizadora, além do acervo da Secretaria Geral da Faculdade de Ciências Médicas das décadas de 1960 a 1990, e pessoal do primeiro Diretor da Faculdade foram organizados e são conservados pelo Siarq.

Em um trabalho detalhado de reconstituição histórico-documental, Neire do Rossio Martins (2012) fornece importantes subsídios sobre a história dos arquivos da Unicamp. Relata que o Arquivo Edgard Leuenroth, reunindo o acervo desse militante anarquista, foi doado à Universidade por intervenção de professores do Instituto de Filosofia e Ciências Humanas e viabilizou a conservação de documentos da esquerda, num momento de plena ditadura militar. Posteriormente, na década de 1980, foi criado o Centro de Memória da Unicamp - CMU - como "órgão interdisciplinar destinado a promover estudos e pesquisas a partir de fundos documentais e de bibliotecas especializadas" (Martins, 2012, p. 34).

Conforme Martins (2012) a criação do Arquivo Central da Unicamp está inserida no período de modernização das bibliotecas e constituição de acervos pessoais pela Instituição, sendo que foi "no final da década de 1980 e durante a década de 1990 [é] que os projetos de arquivos de universidades tomaram forma" (p. 50). 
A constituição do primeiro espaço destinado à preservação da documentação e constituição de um lugar de memória ocorreu em outubro de 1983, quando foi instalado o Centro de Informação e Difusão Cultural - Cidic -, como órgão complementar subordinado à Reitoria, conforme previsto nos estatutos da Universidade.

\section{A constituição dos setores de arquivos na FCM/Unicamp}

Antes de apresentarmos como se contituiu o setor de arquivos da FCM/Unicamp, faremos rápido percurso sobre as origens da Faculdade de Medicina.

As origens dos debates sobre a criação de um curso de graduação em Medicina em Campinas remontam a década de 1950, anterior à criação da Unicamp. Criado em 1958, na qualidade de instituição de ensino superior pela lei n. 4.966, de 25 de novembro de 1958, iniciou definitivamente suas atividades em 20 de maio de 1963, quando foi proferida a aula inaugural. A Universidade Estadual de Campinas, entretanto, instalou-se definitivamente somente em 1965, pela comissão organizadora, com o professor Zeferino Vaz na presidência. Após a instalação da Unicamp a Faculdade de Medicina de Campinas passou a integrar a Unicamp. Em 1969, pelo decreto n. 52.255, de 30 de julho de 1969, o nome da Faculdade foi alterado para Faculdade de Ciências Médicas. As atividades iniciaram-se provisoriamente nas dependências da Maternidade de Campinas, onde permaneceu até 1965, quando houve um acordo entre as direções da Universidade Estadual de Campinas e a Santa Casa de Misericórdia, para utilização de um espaço específico da Santa Casa com a finalidade de implantar um local para treinamento clínico e cirúrgico dos alunos de graduação. Nessa instituição a Faculdade permaneceu até a construção do Hospital de Clínicas da Unicamp no campus de Barão Geraldo, no ano de 1986.

A preocupação com a conservação documental na FCM data de 1990, portanto, muitos anos após a sua constituição como instituição de ensino. Essa preocupação foi intensificada a partir do ano de 2003, com a realização de uma gestão documental de emergência realizada pelo Arquivo Central do Sistema de Arquivos da Unicamp. Esta gestão ocorreu junto ao Departamento de Medicina Legal extinto em 2001, resultando num total de 700 caixas de papéis, equipamentos, materiais biológicos, provas de crime, etc., cujos trabalhos foram finalizados em 2005 e destinados ao Arquivo Setorial da FCM.

Durante as comemorações dos 40 anos da FCM da Unicamp em 2003, surgiu nova preocupação com a preservação da memória da instituição. Esta reflexão, revisão acerca da história da Faculdade, e das pessoas que a formaram, tiveram como resultado ações isoladas de captação e manutenção de acervos da memória histórica e científica de diferentes áreas da FCM. Além disso, avaliou-se a necessidade de aglutinar em um único polo essas atividades de promoção da memória institucional, resultando na submissão de projeto ao Conselho Nacional de Desenvolvimento Científico e Tecnológico, na tentativa de financiamento para construção de um Centro de Documentação na Faculdade, mas que não foi aprovado.

Em 2006, com a nomeação de uma Comissão Setorial de Arquivos, pelo diretor da FCM da Unicamp, iniciaram-se ações de orientação, conscientização e participação dos servidores e demais colaboradores da instituição, os quais produzem e gerenciam documentos institucionais, visando o trabalho de gestão documental. 
O trabalho educativo em gestão documental possibilitou na Faculdade a correta realização dos ciclos documentais e a avaliação, com base na tabela de temporalidade, resultando na eliminação de documentos acumulados e correta conservação de documentos permanentes que antes estavam armazenados em locais não adequados porão, sótão -, que propiciavam a perda do patrimônio documental da instituição.

Em conjunto ao trabalho educativo em gestão documental, a Comissão Setorial de Arquivos avaliou a existência de acervos permanentes de laboratórios, setores administrativos, ensino e de extensão que estavam preservados em múltiplos lugares dificultando o acesso à pesquisa e gerenciamento de sua conservação. Em resposta a essa situação, a Comissão conseguiu, por meio da Diretoria da Faculdade, a criação, em 2006, de um Centro de Memória e Arquivo, tendo como objetivo inicial centralizar e conservar o acervo Institucional, bem como promover a criação de um grupo de discussão e estudo em História das Ciências da Saúde com o objetivo de promover o desenvolvimento de um campo de atividades didáticas, de pesquisa e de extensão relacionado aos estudos históricos das ciências da saúde.

O Regulamento do Centro de Memória foi aprovado na oitava reunião da Congregação da FCM de 2009, deliberação 504/2009. No segundo artigo do regulamento são apresentados os seus objetivos gerais:

I- Desenvolver uma política de aperfeiçoamento das atividades arquivísticas, compatível com as necessidades de agilização da informação e de eficiência administrativa e acadêmica; II- Promover a interação e a inter-relação das áreas responsáveis pela custódia de documentos considerando a integração das diferentes fases da gestão documental; III- Assegurar condições de conservação, proteção e acesso ao patrimônio documental, na defesa dos interesses da Universidade e dos direitos da comunidade acadêmica; IV- Preservar a memória da Faculdade, protegendo o seu acervo arquivístico, para servir como referência, informação, prova ou fonte de pesquisa científica; V- Integrar o Sistema de Arquivos da Universidade Estadual de Campinas, conforme Deliberação CONSU A-8/1995. (Deliberação da congregação da FCM/Unicamp n. 504, 2009, p. 4)

O regulamento do Centro de Memória e Arquivo da FCM observa a preocupação com a preservação e gerenciamento dos arquivos institucionais nos três ciclos documentais e desde a formação da Comissão Setorial de Arquivos são realizados cursos em gestão documental para os secretários e demais colaboradores da Faculdade.

A preservação dos arquivos pessoais localizados nas salas e laboratórios de professores é um resultado do trabalho de orientação em gestão documental, porém os arquivos pessoais de docentes e demais colaboradores doados à instituição, após aprovação, são integrados ao patrimônio da Faculdade.

O CMA/FCM ocupa um espaço físico de $400 \mathrm{~m}^{2}$ distribuídos da seguinte forma: área de recepção, atendimento ao pesquisador e exposição, área do acervo histórico, sala do Grupo de Estudos História das Ciências da Saúde, espaço para conservação e processamento técnico da documentação. Os documentos preservados no CMA/FCM apresentam dois históricos de destinação, a doação de acervos pessoais localizados fora da Faculdade, pertencentes, principalmente, a professores. Este processo de doação inicia-se com a carta de intenção de doação emitida pelo titular do acervo à Instituição; 
posteriormente é constituído um grupo de trabalho nomeado pelo diretor da Faculdade, constituído por especialistas nas áreas de arquivologia, história, ciências da saúde e biblioteconomia para avaliação se o conjunto documental está de acordo com os objetivos do CMA/FCM.

Os acervos que constituíram arquivos pessoais de professores, doados à Faculdade foram os do professor Bernardo Beiguelman, responsável pela criação do Departamento de Genética Médica na Universidade e da Genética Molecular no país, do professor Mario Mantovani, responsável pela constituição da Liga do Trauma e disciplina do trauma na Universidade, além de superintendente do Hospital de Clínicas da Unicamp quando da sua inauguração. Os conjuntos documentais destes professores possibilitam a compreensão das suas trajetórias enquanto docentes, pesquisadores, administradores, gestores, médicos; trazem, também, fragmentos de suas relações familiares. Nesta reconstituição dos acervos pessoais destacam-se cópias e originais de documentos recebidos e expedidos no período à frente de cargos na instituição - diretor, reitor, próreitor, entre outros -, obras como pesquisador - livros, relatórios do laboratório, entre outros -, e como docente: caderno de disciplinas, anotações de aulas, entre outros. Estes documentos tangenciam o pessoal e o institucional, porém em decorrência de comprovarem as atividades do titular do acervo são mantidos como fundo pessoal, apresentando a indicação no inventário das unidades de procedência.

Os arquivos localizados nas secretarias da Faculdade que passaram pelo trabalho de gestão documental é outro modelo de documentação preservada no setor. Neste caso são transferidos ao CMA/FCM arquivos predominantemente institucionais, documentos permanentes das secretarias dos departamentos, graduação, pós-graduação, centros e núcleos de pesquisa e demais setores administrativos da Faculdade. Os documentos permanentes preservados representam atividades fins de cada setor da Instituição, sendo que a sua produção e guarda estão previstas na tabela de temporalidade.

Nos conjuntos transferidos das áreas da Faculdade é apresentada uma particularidade com relação aos documentos de laboratórios. São espaços caracterizados como locais de produção de conhecimento, pesquisa e ensino pelos docentes, técnicos de laboratórios, discentes de graduação e pós-graduação e demais colaboradores, que produzem arquivos com as atividades meio e fins do setor, tais, como livro de registro de pesquisa, resultados de experimentos, programa de disciplinas, contratos de pesquisa com instituições de financiamento, entre outros. Muitas vezes junto com os arquivos institucionais destes laboratórios são encontrados arquivos pessoais dos professores que foram supervisores dos laboratórios; estes documentos são uma extensão dos arquivos encontrados em suas residências que refletem tanto as trajetórias universitárias como pessoais, tais como: certificados de participação em bancas de pós-graduação, correspondências expedidas em cargos na reitoria, correspondências familiares, entre outros.

Os conjuntos documentais dos laboratórios que passaram pelo trabalho de gestão documental e atualmente estão preservados no CMA/FCM, estão ordenados sob dois fundos arquivísticos; o institucional - denominação do laboratório e o pessoal denominação do professor supervisor dos laboratórios. Até o momento temos os 
seguintes conjuntos documentais: Anatomia Patológica: prof. José Lopes de Faria; Junção Neuromuscular: prof. Oswaldo Vital Brazil; Comunicação e Educação em Saúde: profa. Solange L’Abbate; Centro de Investigação Pediátrica: prof. José Martins Filho; Fisiologia de Órgãos: prof. José Francisco Figueiredo.

\section{A identificação dos arquivos dos diretores}

Os documentos que foram utilizados na pesquisa são: processo de vida funcional Unicamp dos diretores, relatório trienal de docente, processo administrativo de convênios, entrevistas publicadas em periódicos e transcritas nos centros de documentação, portarias do Reitor, discursos de paraninfos dos diretores, notícias publicadas na imprensa, biografias e autobiografias, relatório de gestão dos Reitores, correspondências recebidas e expedidas dos reitores e diretor da FCM, processo Unicamp de regulamentação de cursos, além dos memoriais e relatórios de gestão dos Diretores.

Os acervos pesquisados foram pessoais e institucionais. Os acervos pessoais pesquisados foram: Antonio Augusto de Almeida, localizado no Arquivo Central/Unicamp, José Lopes de Faria e José Martins Filho, localizados no CMA/FCM, Luiz Sergio Leonardi, localizado na residência.

Os documentos-base da pesquisa desde o início foram os memoriais dos diretores e os relatórios de gestão entregues ao reitor da Universidade no término de seus mandatos. Os memoriais pelas suas particularidades - informações pessoais - deixam-nos com uma dúvida, ou seja, seriam pessoais ou institucionais? Este questionamento não encontra uma resposta única, pois quando os memoriais foram apresentados à comissão de corpo docente junto à instituição, como exigência para contratação, concursos de títulos e mudança de regime, os mesmos deixaram de ser pessoais e tornaram-se institucionais, por representarem uma atividade da instituição e da docência. De outro lado, o mesmo memorial entregue na instituição, quando apresentado como cópia guardada com o titular do documento; faz parte de uma atividade pessoal, entrando no fundo pessoal do seu autor.

Um balanço geral dos documentos levantados das catorze gestões mostra que não foram encontrados quatro relatórios de gestão e seis memoriais. Para solucionar este problema foram pesquisados os fundos pessoais dos diretores que estão preservados na Universidade e encaminhado um ofício aos ex-diretores para auxílio dessas lacunas.

$\mathrm{O}$ acervo do prof. Antonio Augusto de Almeida foi doado pelos familiares após a morte do professor: documenta sua trajetória na docência, além de manuscritos dos primeiros anos da Faculdade. No segundo caso os documentos pessoais foram organizados junto com os institucionais localizados no laboratório do prof. José Lopes de Faria, no Departamento de Anatomia Patológica, no acervo pessoal do prof. José Martins Filho que estava reunido em conjunto com o acervo institucional do Centro de Investigação Pediátrica. Por último, o do prof.. Sérgio Leonardi viabilizou o acesso de cópias de documentos existentes em sua residência, em resposta à nossa solicitação.

Entre os documentos institucionais consultados destacam-se: Fundo Secretaria Geral - Arquivo Central da Unicamp/Siarq -, processos vida pessoal e administrativos (Arquivo Central/Unicamp), fundo Comissão de Corpo Docente - Centro de Memória FCM. No quadro 1 apresentação a relação completa dos fundos consultados. 
Quadro 1 -

Tabela de fundos consultados para estudo de cada gestão.

\begin{tabular}{|c|c|c|c|}
\hline Diretor & Fundos institucionais & Fundos pessoais & $\begin{array}{l}\text { Documentos } \\
\text { particulares }\end{array}$ \\
\hline $\begin{array}{l}\text { Antonio Augusto de } \\
\text { Almeida }\end{array}$ & $\begin{array}{l}\text { Secretaria } \\
\text { processos administrativos } \\
\text { (vida pessoal e convênios). }\end{array}$ & $\begin{array}{l}\text { Antonio Augusto de } \\
\text { Almeida }\end{array}$ & \\
\hline $\begin{array}{l}\text { Silvio dos Santos } \\
\text { Carvalhal }\end{array}$ & $\begin{array}{lr}\text { Secretaria } & \text { Geral, } \\
\text { processos Administrativos }\end{array}$ & & \\
\hline $\begin{array}{ll}\text { José } & \text { Aristodemo } \\
\text { Pinotti } & \end{array}$ & $\begin{array}{l}\text { Comissão de corpo } \\
\text { docente }\end{array}$ & & \\
\hline José Lopes de Faria & $\begin{array}{l}\text { Processos administrativos } \\
\text { (vida pessoal e convênios) }\end{array}$ & José Lopes de Faria & \\
\hline Luiz Sergio Leonardi & & & $\begin{array}{l}\text { Relatório } \\
\text { Gestão } \\
\text { Memorial }\end{array}$ \\
\hline $\begin{array}{lr}\text { Antonio } & \text { Frederico } \\
\text { Novaes de Magalhães }\end{array}$ & $\begin{array}{l}\text { Processos administrativos } \\
\text { (vida pessoal e convênios) }\end{array}$ & & \\
\hline José Martins Filho & $\begin{array}{l}\text { Processos administrativos } \\
\text { (vida pessoal e convênios) }\end{array}$ & José Martins Filho & \\
\hline Luis Alberto Magna & $\begin{array}{l}\text { Processos administrativos } \\
\text { (vida pessoal e convênios) }\end{array}$ & & \\
\hline $\begin{array}{ll}\text { Fernando } & \text { Ferreira } \\
\text { Costa } & \end{array}$ & $\begin{array}{l}\text { Comissão de Corpo } \\
\text { Docente, Diretoria/FCM }\end{array}$ & & \\
\hline $\begin{array}{l}\text { Mario José Abdalla } \\
\text { Saad }\end{array}$ & $\begin{array}{l}\text { Comissão de Corpo } \\
\text { Docente. Diretoria/FCM }\end{array}$ & & \\
\hline $\begin{array}{l}\text { Lilian Tereza Lavras } \\
\text { Costallat }\end{array}$ & $\begin{array}{l}\text { Comissão de Corpo } \\
\text { Docente, Diretoria/FCM }\end{array}$ & & \\
\hline $\begin{array}{l}\text { José Antonio Rocha } \\
\text { Gontijo }\end{array}$ & $\begin{array}{l}\text { Comissão de Corpo } \\
\text { Docente, Diretoria/FCM }\end{array}$ & & \\
\hline
\end{tabular}

\section{Considerações finais}

As principais questões apresentadas neste trabalho salientam a historicidade do processo de arquivamento ao longo dos tempos, bem como sua inserção na modernidade. Ao analisar aspectos históricos da constituição dos arquivos da Unicamp e da Faculdade de Ciências Médicas destaca-se a importância que tiveram institucionalmente e para as pesquisas com base documental. De outro lado mostrou-se a necessidade de trabalhar com a caracterização dos arquivos pessoais e institucionais, assim como sobre a política e os processos de doação dos acervos documentais da instituição, contextualizando a origem de produção, acumulação e organização dos fundos documentais.

Nesse sentido, as observações feitas por Bloch (2001), sobre o as fontes documentais são, ainda, oportunas:

a despeito do que às vezes parecem imaginar os iniciantes, os documentos não surgem, aqui ou ali, por efeito [de não se sabe] qual misterioso decreto dos deuses. Sua presença ou ausência em tais arquivos, em tal biblioteca, em tal solo deriva de causas humanas que não 
escapam de modo algum à análise, e aos problemas que sua transmissão coloca, longe de terem apenas o alcance de exercícios de técnicos, tocam eles mesmos no mais íntimo da vida do passado, pois o que se encontra assim posto em jogo é nada menos que a passagem da lembrança através de gerações. (p. 83)

\section{Referências}

AMARAL, Ivan Luiz Martins Franco do; NUNES, Everardo Duarte. Os conceitos de gestão e administração: aplicação ao estudo das gestões dos diretores da Faculdade de Ciências Médicas da Universidade Estadual de Campinas. Regae - Revista de Gestão e Avaliação Educacional, Santa Maria, v. 6 n. 13, 2017 p. 67-81

ARQUIVO NACIONAL. Dicionário brasileiro de terminologia arquivística. 2004. Disponível em http://www.arquivonacional.gov.br/download/dic term arq.pdf. Acesso em 2 nov. 2008

BEHREND, Marinez Terezinha. Resgatando a construção de tabelas de temporalidade de documentos. Porto Alegre: Ufrgs, 2011. $65 \mathrm{f}$. Monografia (trabalho de conclusão de curso). Faculdade de Biblioteconomia e Comunicação, Universidade Federal do Rio Grande do Sul. Disponível em http://www.lume.ufrgs.br/handle/10183/40239. Acesso em 19 jul. 2017.

BELLOTO, Heloísa Liberalli. Universidade e arquivo: perfil, história e convergência. TransInformação. v. 1, n. 3, 1989, p. 15-28.

BELLOTO, Heloísa Liberalli. Arquivos permanentes: tratamento documental. Rio de Janeiro: FGV, 2004.

$\mathrm{BLOCH}$, Marc. Apologia da história ou ofício do historiador. Rio de Janeiro: Jorge Zahar, 2001.

BRUYNE, Paul de; HERMAN, Jacques; SCHOUTHEETE, Marc de. Dinâmica da pesquisa em ciências sociais: os polos da prática metodológica. Rio de Janeiro: Francisco Alves, 1982.

CAMARGO, Ana Maria de Almeida; GORLART, Silvana. Tempo e circunstância. São Paulo: Instituto Fernando Henrique Cardoso, 2007.

COOK, Terry. Arquivos pessoais e arquivos institucionais: para um entendimento arquivístico comum da formação da memória em um mundo pós-moderno. Estudos Históricos, v. 11, n. 21, 1998, p. 129-149.

DUCROT, Ariane A classificação dos arquivos pessoais e familiares. Revista Estudos históricos, Rio de Janeiro, n. 21, 1998, p. 151-168. Disponível em: http://bibliotecadigital.fgv.br/ojs/index.php/reh/article/view/2059/1198. Acesso em $9 \mathrm{dez}$. 2015.

DIAS, Camila Delmondes; SILVA, João Luiz de Carvalho Pinto e; CRUZ, Maria Alice; SAAD, Mario José Abdall; FILHO PEREIRA; Rogério Antunes; PEREIRA, Rosa Ines Costa. FCM 50 anos: a realidade ultrapassou o sonho. Campinas: FCM/Unicamp, 2013.

ESTADO VIRTUAL. Sistema nacional de arquivos: Sinar. Disponível em https://www.estadovirtual.com.br/sinar. Acesso em 19 jul. 2017.

HORA, Sérgio Ricardo Almeida da; SATURNINO, Luyz Paullo Targino; SANTOS, Eliete Correia dos. A evolução do arquivo e da arquivologia na perspectiva da história. WebArtigos, 26 fev.2010. Disponível em http://www.webartigos.com/artigos/a-evolucaodo-arquivo-e-da-arquivologia-na-perspectiva-da-historia/33326/. Acesso em 19 jul. 2017. 
LOPES, Uberdan dos Santos. Arquivos e a organização da gestão documental. Revista $A C B$ : Biblioteconomia em Santa Catarina, v. 9, 2004, p. 113-122. Disponível em https://revista.acbsc.org.br/racb/article/view/412/523. Acesso em 19 jul. 2017.

MEDEIROS, Nilcéia Lage de; AMARAL, Cléia Márcia Gomes do. A representação do ciclo vital dos documentos: uma discussão sob a ótica da gestão de documentos. Em Questão, Porto Alegre: Ufrgs, v. 16, n. 2, 2010, p. 297-310. Disponível em http://seer.ufrgs.br/EmQuestao/article/viewFile/15108/1046. Acesso em 19 jul. 2017.

MARTINS, Neire do Rossio. Memória universitária: o arquivo central do sistema de arquivos da Universidade Estadual de Campinas (1980-1995). Campinas: Unicamp, 2012. 230f. Dissertação (mestrado em Educação). Universidade Estadual de Campinas, Faculdade de Educação.

MOURA, Maria Madalena Arruda de; GARCIA, Machado. Os documentos pessoais no espaço público. Revista Estudos Históricos, v. 11, n. 21, 1998, p. 175-187. Disponível em: http://bibliotecadigital.fgv.br/ojs/index.php/reh/article/view/2070/1209. Acesso em 22 mar. 2017.

PAES, Marilena Leite. Arquivos: teoria e prática. Rio de Janeiro: FGV, 2002.

PRADO, Heloisa de Almeida. A técnica de arquivar. São Paulo: T. Queiroz, 1986.

PRESIDÊNCIA DA REPÚBLICA. Lei n. 8.159 de 8 de janeiro de 1991. Disponível em http://www.planalto.gov.br/ccivil 03/leis/L8159.htm. Acesso em 21 jul. 2017.

SILVA, Welder Antônio. Retrospectiva da arquivística brasileira no século XX. Rio de Janeiro: Unirio, 2002, 96f. Monografia (trabalho de conclusão de curso). Escola de Arquivologia, Universidade do Rio de Janeiro. Disponível em http://welder.eci.ufmg.br/wpcontent/uploads/2014/08/Welder-Ant\%C3\%B4nio-Silva-Monografia.pdf. Acesso em 19 jul. 2017.

SANTOS, Paulo Elian. Uma abordagem arquivística: os documentos de um laboratório das ciências biomédicas. História, Ciências, Saúde - Manguinhos, Rio de Janeiro, v. 19, n. 1, 2012, $\quad$ p. 303-323. $\quad$ Disponível em http://www.scielo.br/scielo.php?script=sci arttext\&pid=S0104-59702012000100016. Acesso em 3 jan. 2016.

SOUSA, Renato Tarcisio Barbosa de. Os princípios arquivísticos e o conceito de classificação. In: RODRIGUES, Georgete Medleg; LOPES, Ilza Leite (org.). Organização e representação do conhecimento na perspectiva da ciência da Informação. Brasília: Thesaurus, 2003, v. 2, p. 240-269.

SOUSA, Renato Tarcisio Barbosa de. Classificação de documentos arquivísticos: trajetória de um conceito. Arquivistica.net, Rio de Janeiro, v. 2, n. 2, 2006, p. 120-142. Disponível em http://www.arquivistica.net. Acesso em 19 jul. 2017.

Ivan Luiz Martins Franco do Amaral é assistente administrativo no Centro de Memória e Arquivo da Faculdade de Ciências Médicas da Unicamp e estudante no curso de mestrado em Saúde Coletiva na mesma instituição.

Orcid: https://orcid.org/0000-0003-2374-4099.

Endereço: Rua Tessália Vieira de Camargo, 126 - 13083-887 - Campinas - SP Brasil.

E-mail: ivanfa@fcm.unicamp.br. 
Everardo Duarte Nunes é doutor em Ciências e professor colaborador no Departamento de Saúde Coletiva da Faculdade de Ciências Médicas da Unicamp. Orcid: https://orcid.org/0000-0002-2285-7473.

Endereço: Rua Tessália Vieira de Camargo, 126 - 13083-887 - Campinas - SP Brasil.

E-mail: evernunes@uol.com.br.

Recebido em 8 de agosto de 2018.

Aceito em 12 de novembro de 2018.

(c) (i) 